\title{
Sex and Gender Equity in Research and Publishing: International Journal of Cardiovascular Sciences endorses SAGER Guidelines
}

\author{
Claudio Tinoco Mesquita ${ }^{1,2,3}$ and Aline Goneli de Lacerda ${ }^{1,4}{ }^{10}$ \\ Programa de Pós-Graduação em Ciências Cardiovasculares, Universidade Federal Fluminense (UFF), ${ }^{1}$ Niterói, RJ - Brazil \\ Hospital Pró-Cardíaco, ${ }^{2}$ Rio de Janeiro, $R J$ - Brazil \\ Hospital Vitória e Samaritano da Barra, ${ }^{3}$ Rio de Janeiro, $R J$ - Brazil \\ Programa de Pós-Graduação em Comunicação, Universidade Federal Fluminense (UFF), ${ }^{4}$ Rio de Janeiro, RJ - Brazil
}

"I raise up my voice - not so I can shout, but so that those without a voice can be heard...we cannot succeed when half of us are held back."

Malala Yousafzai

According to the recently published "Cardiovascular Statistics - Brazil 2020", ${ }^{1}$ mortality from cardiovascular diseases (CVD) is proportionally higher in women compared to men. The INTERHEART study demonstrated that the population attributable risk for myocardial infarction associated with modifiable risk factors of smoking, alcohol use, high-risk diet, and physical inactivity, was significantly higher among women than men. ${ }^{2}$ Evidence from the VIRGO study (Variation in Recovery: Role of Gender on Outcomes of Young Acute Myocardial Infarction [AMI] Patients) indicates that both health professionals and women are unaware or neglect the development of cardiovascular heart disease (CHD) and the presence of cardiovascular risk factors in women.

Women are underrepresented in cardiovascular disease trials despite known sex differences across a broad range of risk, prevention, treatment, and outcome parameters. Gender influences many aspects of disease like its pathophysiology and clinical presentation, response to treatment, clinicians' behavior, and access to health care, ${ }^{3,4}$ and now it is clear that research must

\section{Keywords}

Cardiovascular Diseases/mortality; Risk Factors; Epidemiology; Humans; Gender Indentity; Social Determinants of Health; Female; Women's Health Services. consider this to promote better diagnosis and treatment, and gender equity in health care.

How can scientific journals strengthen sex and gender equity in research and publishing? In many ways, like promoting research in the field. Recently the International Journal of Cardiovascular Sciences made a call for articles about cardiovascular diseases in women and published an entire edition dedicated to subject. In that edition, Meira Ferreira et al., ${ }^{4}$ published a review article about closing the gender gap in ischemic heart disease (IHD) and myocardial infarction. These authors showed that the prevalence of IHD increased in both sexes from 1990 to 2017 in Brazil, with differences in sex distribution among geographical regions. For example, there were 22\% more IHD cases in women in the southeast region than in women in the northeast region. ${ }^{4}$ In the same edition, Gazzilli5 highlighted the increase in annual proportional mortality from IHD in women in recent years, with an age-standardized incidence of 104 per 100,000 population for males and 58 per 100,000 population for females. ${ }^{5}$

Another important step in the promotion of gender equity is the adoption of guidelines to improve the reporting of sex and gender in research across disciplines. A panel of 13 experts developed the SAGER (Sex and Gender Equity in Research) guidelines to guide authors in preparing manuscripts and editors in assessing the inclusion of sex and gender into manuscripts as an integral part of the editorial process. ${ }^{6}$ Table 1 lists a summary of recommendations from the SAGER guidelines that may be easily adopted by authors. The International Journal of Cardiovascular Sciences is including the SAGER guidelines in its policy and will encourage the submitting 
Table 1 - Sex and Gender Equity in Research (SAGER) guidelines

\section{General principles}

- Use the words sex and gender carefully.

- Use the term sex in animal studies.

-Where subjects can be differentiated by gender, research should take this into account.

Recommendations per section of the article

Title and Abstract

Introduction

Methods

Results
- the title and the abstract of articles should specify the sex/gender of research subjects

- specify the sex of cells and tissues in cell biological, molecular biological, and biochemical studies

- authors should report if sex/gender differences may be expected.

- authors should describe how sex/gender was determined (self-report, examination, genetic testing)

- in medical device testing, explain whether the device will be used by all genders and if it has been tested with this in mind

- data should be routinely presented disaggregated by sex

- sex- and gender-based analyses should be carried out, if appropriate, and reported regardless of positive or negative outcome.

- implications of sex and gender on study results and analysis should be discussed. If a sex and gender analysis was not conducted, the rationale should be given, and authors should discuss the implications of the lack of such analysis in interpreting the results.

Adapted from Heidari ,et al. ${ }^{6}$

authors to follow these recommendations. We will make progressive changes in the Scholar One submission system to increase the compliance to these guidelines and promote educational activities to revisors and authors to facilitate the adherence to the SAGER guidelines.

There is a lot yet to be done to close the gap of sex and gender equity in research, publication, and in many other aspects of life. Women need to be included, respected, empowered, and adequately represented in many aspects of the scientific community. ${ }^{7,8}$ Men and women publish a comparable number of papers per year and have equivalent career impact for the same total number of publications. The decrease in productivity observed in women can be largely explained by different publishing career length and dropout rates. ${ }^{9}$

We must use our knowledge and wisdom to offer opportunities to close the gender gap to researchers and to our patients. The International Journal of Cardiovascular Sciences is making this call to the cardiovascular scientific community.

\section{References}

1. Moraes De Oliveira GM, Brant LCC, Polanczyk CA, Biolo A, Nascimento BR, Malta DC, et al. Cardiovascular statistics-brazil 2020. Arq Bras Cardiol.2020;115(3):308-439.

2. Rosengren A, Hawken S, Ounpuu S, Sliwa K, Zubaid M, Almahmeed $\mathrm{WM}$, et al. Association of psychosocial risk factors with risk of acute myocardial infarction in 11119 cases and 13648 controls from 52 countries (the INTERHEART study): case-control study. Lancet.2004;364(9438):953-62.

3. O'Neil A, Scovelle A J, Milner A J, Kavanagh A. Gender/sex as a social determinant of cardiovascular risk. Circulation.2018;137(8):854-64.

4. Ferreira M C M, Oliveira M, Paiva MS, Lemke V, Mangione F. Closing the Gender Gap in Ischemic Heart Diseases and Myocardial Infarction. International Journal of Cardiovascular Sciences (2021) doi:10.36660/ijcs.20210001.

5. Gazzilli, M. How the Gender Gap Affects the Incidence and Prognosis of Cardiovascular Disease. Int J Cardovasc Sci. 2021;34(4):471-83. doi:10.36660/ijcs.20210132.

6. Heidari S, Babor TF, Castro P, Tort S, Curno M. Equidade de sexo e gênero na pesquisa: fundamentação das diretrizes SAGER e uso recomendado. Epidemiol Serv Saude.2017;26(03):665-75.

7. Marques-Santos C, Oliveira GM. Are Women the Fragile Sex? Or are They the Singular Sex? Int J Cardiovasc Sci. 2021;34(9):344-6. doi:10.36660/ijcs.20210171.

8. Clayton J A, Tannenbaum C. Reporting sex, gender, or both in clinical research? JAMA .2016;316(18):1863-4.

9. Huang J, Gates AJ, Sinatra R, Barabasi AL,Barabasi B. Historical comparison of gender inequality in scientific careers across countries and disciplines. Proc Natl Acad Sci USA. 2020;117(9):4609-16. 